\title{
To evaluate the impact of a nurse-led JIA education program on parental satisfaction regarding knowledge of JIA and its management
}

\author{
J Jones ${ }^{1 *}$, J Munro ${ }^{1,2,3}$, T Williams ${ }^{1,3}$, A Augustine $^{2}$, K Taylor $^{1,2}$, S Piper ${ }^{2}$, R Allen ${ }^{1}$, J Akikusa ${ }^{1}$ \\ From 18th Pediatric Rheumatology European Society (PReS) Congress \\ Bruges, Belgium. 14-18 September 2011
}

\section{Background}

In 2005 the Arthritis and Musculoskeletal Quality Improvement Project (AMQuiP) at the Royal Children's Hospital ( $\mathrm{RCH})$ and Monash Children's Hospital found over $50 \%$ of families wanted more education about JIA. A nurse-led education program was established.

\section{Aim}

To evaluate parental satisfaction with the JIA education provided as part of the new model of care for JIA at the $\mathrm{RCH}$.

\section{Methods}

The RCH Rheumatology Database was used to identify all children diagnosed with JIA at RCH in 2009 according to ILAR (2001).

The families of those who had undertaken education were invited to complete the questionnaire used previously in the AMQuiP project. The questionnaire surveyed satisfaction regarding information provided about:

I JIA

- Medications

- Self management

- Managing disease flares

- Support services

- Emotional management

- School management.

Improvement in satisfaction was determined by examining the change in the percent of respondents indicating a need for more education when compared with those in 2005.

\section{Results}

Sixty children were diagnosed with JIA at RCH in 2009, $77 \%$ of these families who had undertaken JIA education were invited to complete the questionnaire used previously in the AMQuiP project. Completed questionnaires were received from $63 \%$ of families. There was a substantial improvement of between $22-48 \%$ in parental satisfaction in all education related domains. The greatest improvements were in the disease $(38 \%)$ and treatment (42\%) domains. The areas with the least improvement were related to self management $(22 \%)$ and support services (26\%).

\section{Conclusion}

The inclusion of a nurse-led education program has substantially improved parental satisfaction regarding their knowledge of issues integral to caring for children with JIA.

\section{Author details \\ 'Royal Children's Hospital Melbourne, Australia. ${ }^{2}$ Monash Children's Hospital Clayton Australia. ${ }^{3}$ The Murdoch Childrens Research Institute Melbourne Australia. \\ Published: 14 September 2011}

\section{doi:10.1186/1546-0096-9-S1-O24}

Cite this article as: Jones et al:: To evaluate the impact of a nurse-led JIA education program on parental satisfaction regarding knowledge of JIA and its management. Pediatric Rheumatology 2011 9(Suppl 1):O24.

* Correspondence: julieS.jones@rch.org.au

${ }^{1}$ Royal Children's Hospital Melbourne, Australia

Full list of author information is available at the end of the article

(c) 2011 Jones et al; licensee BioMed Central Ltd. This is an open access article distributed under the terms of the Creative Commons 